\title{
Editorial
}

\section{Continuous-Flow Catalysis}

\author{
Sándor B. Ötvös
}

Citation: Ötvös, S.B.

Continuous-Flow Catalysis. Catalysts 2021, 11, 1066. https://doi.org/ $10.3390 /$ catal11091066

Received: 18 August 2021

Accepted: 27 August 2021

Published: 31 August 2021

Publisher's Note: MDPI stays neutral with regard to jurisdictional claims in published maps and institutional affiliations.

Copyright: (C) 2021 by the author. Licensee MDPI, Basel, Switzerland. This article is an open access article distributed under the terms and conditions of the Creative Commons Attribution (CC BY) license (https:// creativecommons.org/licenses/by/ $4.0 /)$.
Institute of Chemistry, University of Graz, NAWI Graz, Heinrichstrasse 28, A-8010 Graz, Austria; sandor.oetvoes@uni-graz.at

During the past twenty years, flow chemistry has emerged as an enabling tool to simplify, accelerate, integrate, scale-up and automatize chemical reactions [1]. Nowadays, it exhibits an inherently safer and greener nature over classical batch processes. Flow chemistry and catalysis have been demonstrated to represent an ideal match for the sustainable synthesis of an array of valuable products including biologically active substances, natural products and active pharmaceutical ingredients (APIs) [2-4]. Either heterogeneous or homogeneous catalytic reactions can be significantly advanced by the technical merits of continuous-flow processing and microreaction technology. Reactions involving gases, hazardous substances and reactive intermediates, as well as photo- and electrocatalytic transformations, can especially be facilitated by the benefits of flow chemistry. With increasing societal and economical pressure on sustainability, costs and quality, the pharmaceutical industry is gradually comprehending the concept of continuous-flow manufacturing, whilst the FDA (U.S. Food and Drug Administration) and the EMA (European Medicines Agency) are actively exploring this technology and its potentials [5]. This Special Issue therefore covered recent research on the subject of all aspects of catalytic reactions performed in various continuous-flow systems.

In a review paper by Fuse and co-workers, recent continuous-flow processes using metal-free homogeneous catalysts were surveyed [6]. The review compares continuousflow results with conventional batch experiments and highlights the benefits and also the disadvantages of metal-free catalytic approaches utilizing either acidic, basic or miscellaneous catalysts.

In an excellent contribution by Tamborini and co-workers, flow-based chemoenzymatic synthesis of selected APIs is presented [7]. A bioreactor was exploited to yield valuable amide and ester intermediates, which were next processed into the final API by means of in-line purification and continuous-flow hydrogenation.

Sá and co-workers investigated the effect of palladium doping on a nano-nickel catalyst during the hydrogenation of sulcatone under continuous-flow conditions [8]. The authors observed that doping enhanced hydrogen activation on the catalyst, which was found to be a rate-limiting step using kinetic isotopic measurements and theoretical calculations.

Gruber-Woelfler and co-workers reported the optimization of a chemoenzymatic tandem reaction under flow conditions and demonstrated its application for the synthesis of pharmacologically active substances, resveratrol and pterostilbene [9]. The process involved the enzymatic decarboxylation of coumaric acid followed by a telescoped Heck coupling of the corresponding vinylphenol intermediate with an aryl iodide using a heterogeneous palladium catalyst in a packed bed reactor.

Selva and co-workers reported a two-step sequence by combining batch and flow protocols for upgrading aminodiol regioisomers derived from glycerol [10]. Initially, catalyst-free $\mathrm{N}$-acetylation furnished the corresponding amide intermediates, which were next transformed into the desired amide-acetal products by means of selective continuousflow acetalization in the presence of a solid acid catalyst.

Len and co-workers demonstrated an interesting continuous-flow protocol for the oligomerization of glycerol under microwave activation in the presence of potassium carbonate as a readily available homogeneous basic catalyst [11]. The effects of temperature 
and residence time were thoroughly investigated to strategically control the distribution of oligomers.

This collection gave excellent recent examples on how catalysis and flow chemistry can jointly advance the synthesis and manufacture of valuable products and their useful intermediates.

\section{References}

1. Plutschack, M.B.; Pieber, B.; Gilmore, K.; Seeberger, P.H. The Hitchhiker's Guide to Flow Chemistry. Chem. Rev. 2017, 117, 11796-11893. [CrossRef] [PubMed]

2. Pastre, J.C.; Browne, D.L.; Ley, S.V. Flow chemistry syntheses of natural products. Chem. Soc. Rev. 2013, 42, 8849-8869. [CrossRef] [PubMed]

3. Gérardy, R.; Emmanuel, N.; Toupy, T.; Kassin, V.-E.; Tshibalonza, N.N.; Schmitz, M.; Monbaliu, J.-C.M. Continuous Flow Organic Chemistry: Successes and Pitfalls at the Interface with Current Societal Challenges. Eur. J. Org. Chem. 2018, 2018, 2301-2351. [CrossRef]

4. Ötvös, S.B.; Kappe, C.O. Continuous Flow Asymmetric Synthesis of Chiral Active Pharmaceutical Ingredients and their Advanced Intermediates. Green Chem. 2021. [CrossRef]

5. McWilliams, J.C.; Allian, A.D.; Opalka, S.M.; May, S.A.; Journet, M.; Braden, T.M. The Evolving State of Continuous Processing in Pharmaceutical API Manufacturing: A Survey of Pharmaceutical Companies and Contract Manufacturing Organizations. Org. Process Res. Dev. 2018, 22, 1143-1166. [CrossRef]

6. Sugisawa, N.; Nakamura, H.; Fuse, S. Recent Advances in Continuous-Flow Reactions Using Metal-Free Homogeneous Catalysts. Catalysts 2020, 10, 1321. [CrossRef]

7. Annunziata, F.; Letizia Contente, M.; Betti, D.; Pinna, C.; Molinari, F.; Tamborini, L.; Pinto, A. Efficient Chemo-Enzymatic Flow Synthesis of High Value Amides and Esters. Catalysts 2020, 10, 939. [CrossRef]

8. Goszewska, I.; Zienkiewicz-Machnik, M.; Błachucki, W.; Kubas, A.; Giziński, D.; Matus, K.; Nikiforow, K.; Lisovytskiy, D.; Śrębowata, A.; Szlachetko, J.; et al. Boosting the Performance of Nano-Ni Catalysts by Palladium Doping in Flow Hydrogenation of Sulcatone. Catalysts 2020, 10, 1267. [CrossRef]

9. Lackner, F.; Hiebler, K.; Grabner, B.; Gruber-Woelfler, H. Optimization of a Catalytic Chemoenzymatic Tandem Reaction for the Synthesis of Natural Stilbenes in Continuous Flow. Catalysts 2020, 10, 1404. [CrossRef]

10. Rigo, D.; Carmo Dos Santos, N.A.; Perosa, A.; Selva, M. Concatenated Batch and Continuous Flow Procedures for the Upgrading of Glycerol-Derived Aminodiols via N-Acetylation and Acetalization Reactions. Catalysts 2021, 11, 21. [CrossRef]

11. Nguyen, R.; Galy, N.; Alasmary, F.A.; Len, C. Microwave-Assisted Continuous Flow for the Selective Oligomerization of Glycerol. Catalysts 2021, 11, 166. [CrossRef] 